\title{
System performance analysis of Gifford-McMahon cooler
}

\author{
B.J. Huang and S.C. Chang \\ Department of Mechanical Engineering, National Taiwan University, Taipei, Taiwan
}

Received 12 July 1994; revised 12 September 1994

System performance analysis of a Gifford-McMahon (GM) cooler was carried out using the half-cycle mean model of a regenerator and instantaneous solutions of the mass and momentum equations. A PC-based simulation package GMSYS was also developed for system design analysis of a single-stage GM cryocooler. It is shown experimentally that the predicted values agree very well with test results.

Keywords: Gifford-McMahon cooler; system performance analysis; computer simulation

\begin{tabular}{|c|c|c|c|}
\hline \multicolumn{2}{|c|}{ Nomenclature } & \multirow{3}{*}{$\begin{array}{l}Q_{\mathrm{L}} \\
R \\
T_{\mathrm{c}}\end{array}$} & \multirow{3}{*}{$\begin{array}{l}\text { Net cooling capacity }(\mathrm{W}) \\
\text { Gas constant } \\
\text { Compression space temperature }(\mathrm{K})\end{array}$} \\
\hline$A$ & Free flow area of regenerator $\left(\mathrm{m}^{2}\right)$ & & \\
\hline$C_{\mathrm{r}}^{A_{\mathrm{r}}}$ & & & \\
\hline$C_{\mathrm{p}}$ & Constant-pressure heat capacity $\left(\mathrm{J} \mathrm{kg}^{-1} \mathrm{~K}^{-1}\right.$ ) & $T_{\mathrm{e}}$ & Expansion space temperature $(\mathrm{K})$ \\
\hline$C_{\mathrm{v}}$ & Constant-volume heat capacity $\left(\mathrm{J} \mathrm{kg}^{-1} \mathrm{~K}^{-1}\right)$ & $T_{\mathrm{H}}$ & Compressor supplied gas temperature $(\mathrm{K})$ \\
\hline$C_{\mathrm{s}}$ & $\begin{array}{l}\text { Heat capacity of regenerator matrix } \\
\left(\mathrm{J} \mathrm{kg}^{-1} \mathrm{~K}^{-1}\right)\end{array}$ & $\begin{array}{l}t \\
V_{c}\end{array}$ & $\begin{array}{l}\text { Time }(\mathrm{s}) \\
\text { Compression space volume }\left(\mathrm{m}^{3}\right)\end{array}$ \\
\hline$f$ & Reciprocating frequency of displacer $(\mathrm{Hz})$ & $V_{\mathrm{e}}$ & Expansion space volume $\left(\mathrm{m}^{3}\right)$ \\
\hline$L_{\mathrm{r}}$ & Length of regenerator $(\mathrm{m})$ & $V_{\mathrm{r}}$ & Regenerator volume $\left(=A_{\mathrm{o}} L_{\mathrm{r}}\right)\left(\mathrm{m}^{3}\right)$ \\
\hline$\dot{m}_{\mathrm{in}}$ & $\begin{array}{l}\text { Mass flowrate of gas from valve to } \\
\text { compression space }\left(\mathrm{kg} \mathrm{s}^{-1}\right)\end{array}$ & $V_{\text {swept }}$ & Swept volume of displacer $\left(\mathrm{m}^{3}\right)$ \\
\hline$\dot{m}_{\text {out }}$ & $\begin{array}{l}\text { Mass flowrate of gas from compression space } \\
\text { to valve }\left(\mathrm{kg} \mathrm{s}^{-1}\right)\end{array}$ & \multicolumn{2}{|c|}{ Greek letters } \\
\hline$\dot{m}_{\mathrm{r}}$ & Mass flowrate through regenerator $\left(\mathrm{kg} \mathrm{s}^{-1}\right)$ & $\alpha, \beta$ & Coefficients of Darcy's Equation (8) \\
\hline$\dot{m}_{\mathrm{v}}$ & Mass flowrate through valve $\left(\mathrm{kg} \mathrm{s}^{-1}\right)$ & $\gamma$ & $C_{\mathrm{p}} / C_{\mathrm{v}}$ \\
\hline$p_{\mathrm{c}}$ & Gas pressure in compression space $\left(\mathrm{N} \mathrm{m}^{-2}\right)$ & $\epsilon$ & Porosity of regenerator \\
\hline$p_{\mathrm{e}}$ & Gas pressure in expansion space $\left(\mathrm{N} \mathrm{m}^{-2}\right)$ & $\eta$ & Effectiveness of regenerator \\
\hline$p_{\mathrm{H}}$ & Gas pressure supplied by compressor $\left(\mathrm{N} \mathrm{m}^{-2}\right)$ & $\rho_{\mathrm{c}}$ & Gas density in compression space \\
\hline$p_{\mathrm{h}}$ & $\begin{array}{l}\text { Gas pressure in expansion space at state } 2 \\
\left(\mathrm{~N} \mathrm{~m}^{-2}\right)\end{array}$ & $\begin{array}{l}\rho_{\mathrm{e}} \\
\rho_{\mathrm{r}}\end{array}$ & $\begin{array}{l}\text { Gas density in expansion space } \\
\text { Gas density in regenerator }\end{array}$ \\
\hline$p_{\mathrm{L}}$ & Compressor return pressure $\left(\mathrm{N} \mathrm{m}^{-2}\right)$ & $\tau$ & Period of GM cycle, $\tau=1 / f$ \\
\hline$p_{\mathrm{o}}$ & $\begin{array}{l}\text { Gas pressure in expansion space at state } 4 \\
\left(\mathrm{~N} \mathrm{~m}^{-2}\right)\end{array}$ & & \\
\hline
\end{tabular}

The Gifford-McMahon (GM) cooler (Figure 1) belongs to a class of cooling systems utilizing a gas-compression refrigeration cycle. The refrigeration effect of the GM cooler rcsults from a scries of thermodynamic processes acting on the gas, including charging and compression, displacement and heat exchange with the regenerator, expansion and heat absorption (cooling effect), as shown in Figure 2.

It seems that progress in the development of system design tools for GM coolers is still limited since only a few researchers have carried out system performance analysis. Gifford ${ }^{1}$ assumed that the GM cycle is composed of a cycle similar to the Brayton cycle but with an intermediate expansion pressure which varies with the displacer motion and the gas intake/exhaust process. In addition, the two isenthalpic processes of gas moving through the intake and exhaust valves were considered. Gifford ${ }^{1}$ derived an expression for $C O P$ in terms of pressure and temperature ratios based on the ideal analysis.

Thirumaleshwar and Subramanyam ${ }^{2}$ further modified the Gifford model ${ }^{1}$ by considering the thermal losses in the cooler and derived an expression for cooler performance. It was, however, shown experimentally that their analysis over-estimates actual values in practice ${ }^{3}$. 


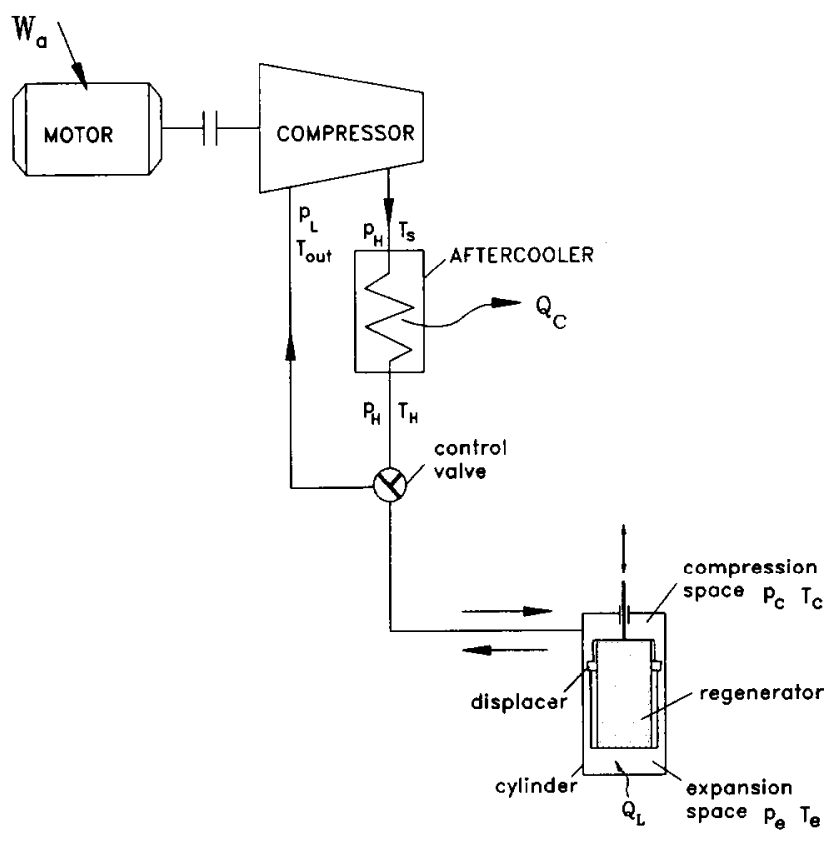

Figure 1 Schematic diagram of GM cryocooler
Instead of using the aforementioned thermodynamic approach ${ }^{1,2}$, Ackermann and Gifford ${ }^{4}$ derived a transient heat transfer model for the regenerator of a GM cooler according to a parallel flow analogy to account for the regenerator loss. The model can only be used, however, to evaluate the regenerator heat transfer property $N T U$ using the test results of a GM cooler.

Minas and Hualde ${ }^{5}$ derived a dynamic model for a GM cooler using a pneumatically-driven displacer. The model includes the dynamic, fluid dynamic and thermodynamic effects and consists of a non-linear time-varying system of differential equations which are solved numerically. The predicted system performance is shown to coincide with experimental results only qualitatively.

To overcome the aforementioned difficulties in the desired analysis, a method of system performance analysis based on a half-cycle mean model is developed here for a GM cooler with a mechanically-driven displacer.

\section{Performance model}

\section{Thermal process of Gifford-McMahon cooler}

For a single-stage GM cooler, the working gas is compressed by the compressor from $p_{\mathrm{L}}$ to $p_{\mathrm{H}}$ and then cooled from $T_{\mathrm{s}}$ to $T_{\mathrm{H}}$ by the aftercooler of the compressor. The
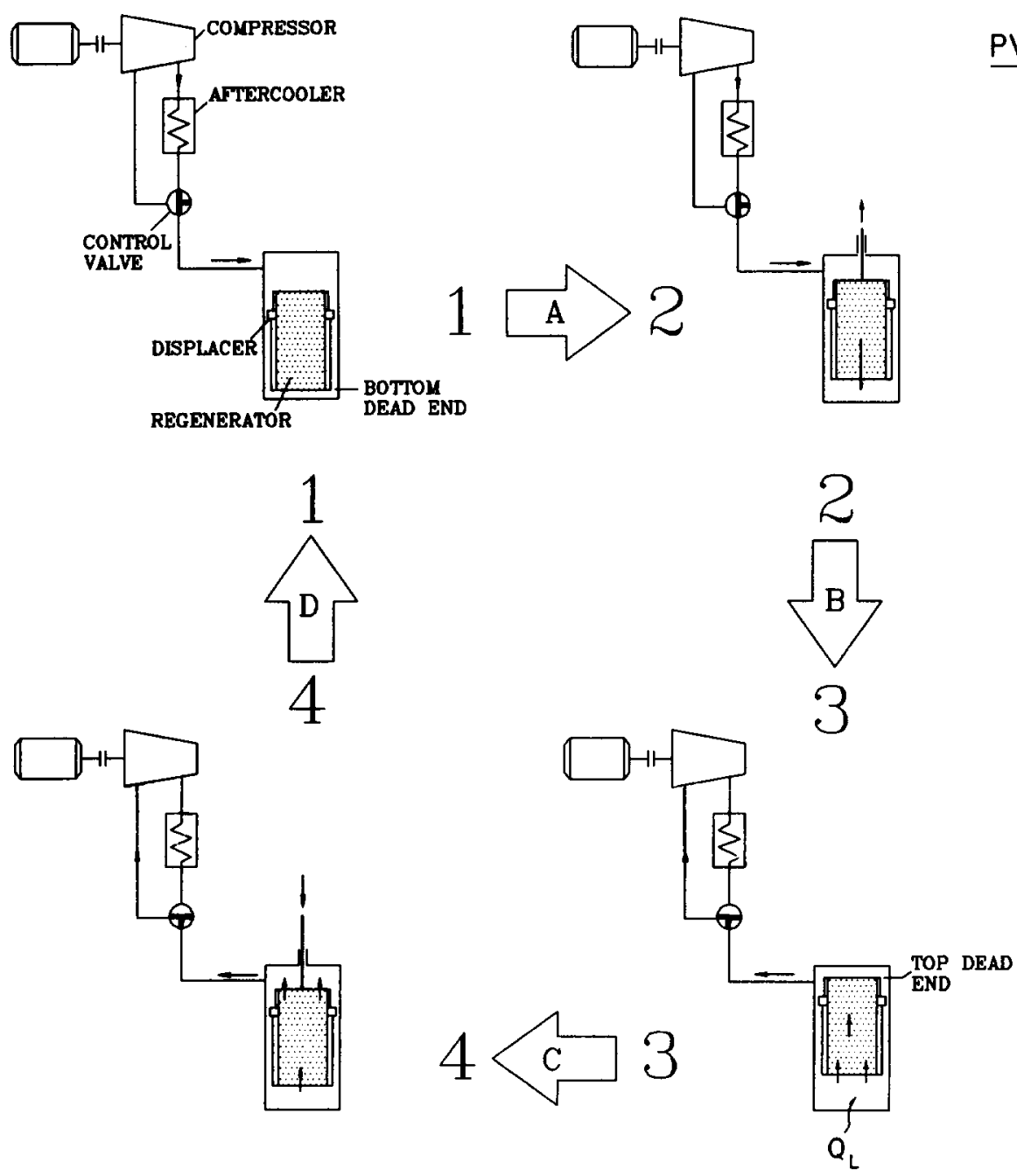

\section{PV Diagram of Expansion Space}
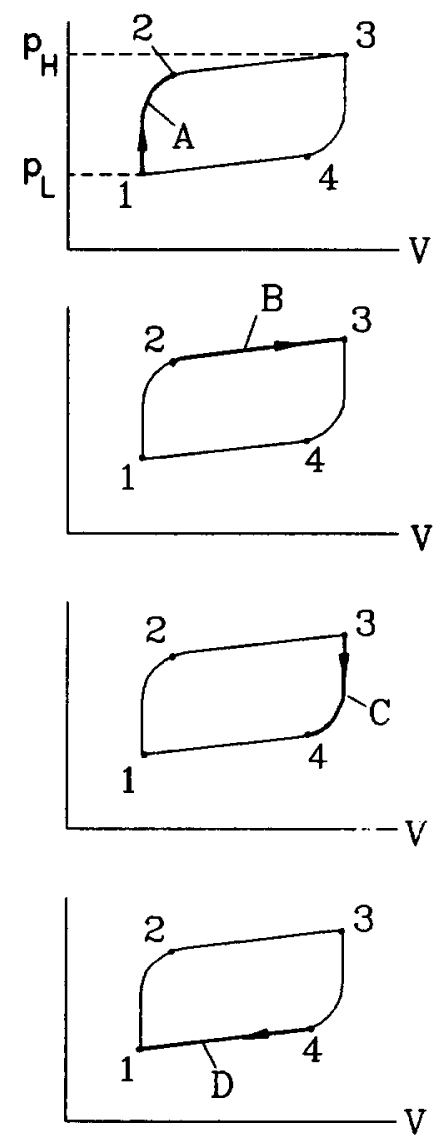

Figure 2 Refrigeration cycle of GM cryocooler 
thermodynamic processes of the gas in a GM cooler can be divided into four stages ( $\sec$ Figure 2):

1 Process $A(1 \rightarrow 2)$ : intake and compression

2 Process B $(2 \rightarrow 3)$ : displacement and heat exchange (gas cooled)

3 Process $C(3 \rightarrow 4)$ : expansion and refrigeration

4 Process D $(4 \rightarrow 1)$ : displacement and heat exchange (gas heated)

In process $A(1 \rightarrow 2)$, the control valve is switched to the intake loop and the regenerator/displacer starts to move upwards from the bottom dead cnd. The volume of the expansion space is $V_{\mathrm{eD}}$ at the beginning (state 1). High pressure gas is then purged into the compression chamber and expels or compresses the residue gas in the expansion space, the connecting tube and the regenerator from a low pressure $p_{1}$ to a higher pressure $p_{2}$.

In process $\mathrm{B}(2 \rightarrow 3)$, the displacer keeps moving upwards and expels the gas in the compression space to the expansion space. During this process, the expelled gas is cooled by the regenerator matrix and mixed with the incoming gas from the compressor. The volume of the compression space becomes $V_{\mathrm{cD}}$ and the pressure in the expansion space becomes $p_{3}$ as the displacer reaches the top dead end, at the end of process B (state 3 ). During process A and B $(1 \rightarrow 3)$, the control valve is switched to the intake loop.

In process $C(3 \rightarrow 4)$, the control valve is switched to the exhaust loop and the displacer starts to move downwards from the top dead end. The gas starts to expand outwards from the expansion space to give rise to the refrigeration effect and flows back to the compressor. The regenerator matrix is meanwhile cooled by the expanded cold gas (or the gas is heated by the regenerator). The gas pressure in the expansion space drops from $p_{3}$ to $p_{4}$ in process $\mathrm{C}$.

In process $\mathrm{D}(4 \rightarrow 1)$, the displacer keeps moving downwards with the valve still in the exhaust loop. The cold gas in the expansion space is expelled to the compression space and cools the regenerator matrix. Meanwhile, part of the gas will flow back to the compressor. The volume of the expansion space changes to $V_{\mathrm{eD}}\left(=V_{1}\right)$ as the displacer reaches the bottom dead end. The temperature distribution in the GM cooler is shown in Figure 3.

Since process A and process B form the gas intake process, the residue gas inside the cooler will be mixed with the gas supplied from the compressor. Hence, the working fluid cannot be clearly defined for the thermodynamics

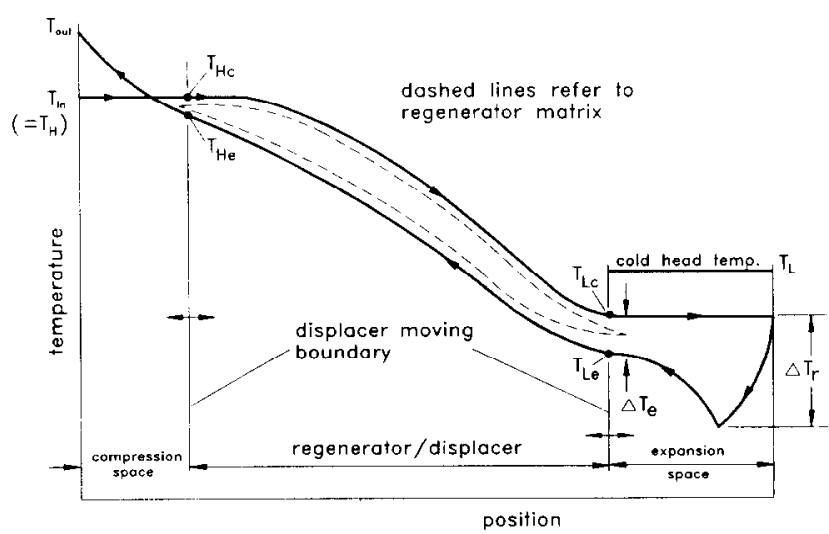

Figure 3 Temperature distribution inside the GM cooler analysis $^{1,2}$. In the present study, mass and momentum equations of the GM cooler will be derived and solved numerically in conjunction with the regenerator energy equation which is derived based on a half-cycle mean concept.

\section{Half-cycle mean model}

The thermal performance of the regenerator can be evaluated by numerically solving the transient heat transfer equations as derived by Ackermann and Gifford ${ }^{4}$. The numerical computation is, however, quite tedious and is subject to numerical problems. To simplify the heat transfer analysis of the regenerator, a so-called 'half-cycle mean model' is developed here.

It is seen that processes A and B involve gas intake and processes $\mathrm{C}$ and $\mathrm{D}$ involve gas exhaust. Therefore, the process taking place in a GM cycle can be divided into two half-cycle periods: namely, the intake period and exhaust period. The gas undergoes a compression process during the intake half-cycle and an expansion/refrigeration process during the exhaust half-cycle. Variables such as temperature, pressure and mass flowrate can be converted into halfcycle mean variables through the following definition

$\bar{x}=\frac{1}{\tau / 2} \int_{0}^{\tau / 2} x(t) \mathrm{d} t$

where $x$ represents the system variable and $\tau$ is the period of the displacer motion $(=1 / f)$.

\section{Governing equations}

Half-cycle mean energy equation of regenerator. The regenerator is an important cold storage component in the GM cycle. The regenerator is used to precool the gas during the intake period (process $A$ and $B$ ). In the exhaust period (process $C$ and $D$ ), the regenerator matrix is cooled by the cold gas. The heat exchange process of the regenerator can be expressed in terms of the effectiveness $\eta$ $=Q_{\text {actual }} / Q_{\max }$, where $Q_{\max }$ is the maximum heat exchange rate and $Q_{\text {actual }}$ is the actual heat exchange rate.

For the regenerator in a GM cooler

$\eta=\frac{H_{\mathrm{h}, \text { in }}-H_{\mathrm{c} \text { in }}}{H_{\mathrm{h}, \text { in }}-H_{\mathrm{c}, \text { out }}}$

where $H_{\text {c,out }}$ and $H_{\text {c,in }}$ are the total enthalpy flows at the regenerator cold end during the exhaust and the intake periods, respectively, and $H_{\mathrm{h}, \text { in }}$ is the total enthalpy flow at the regenerator hot end during the intake period. Here, the total enthalpy flow $H$ is defined as the integration of the rate of enthalpy flow over a half-cycle, i.e.

$H \equiv \int_{\text {half cycle }} \dot{m}(t) C_{\mathrm{p}} T(t) \mathrm{d} t$

Since the operating frequency of a GM cooler is relatively low (around 50-80 $\mathrm{rev} \mathrm{min}^{-1}$ ), the phase shift between the mass flowrate and temperature or pressure is small $^{6}$. Therefore, the half-cycle mean of the product of two variables $x y$ will approximate the product of the halfcycle mean of each product ${ }^{7}$, i.e. $\overline{x y}=\bar{x} \bar{y}$. 
According to the above assumptions, Equation (2) can thus be approximated by

$\eta \approx \frac{\dot{m}_{\mathrm{r}}^{-} C_{\mathrm{p}}\left(\bar{T}_{\mathrm{He}}-\bar{T}_{\mathrm{Le}}\right)}{\dot{m}_{\mathrm{r}} C_{\mathrm{p}}\left(\bar{T}_{\mathrm{Hc}}-\bar{T}_{\mathrm{Le}}\right)}=\frac{\bar{T}_{\mathrm{He}}-\bar{T}_{\mathrm{Le}}}{\bar{T}_{\mathrm{Hc}}-\bar{T}_{\mathrm{Le}}}$

where $\bar{T}_{\mathrm{Hc}}$ and $\bar{T}_{\mathrm{He}}$ are the half-cycle mean temperatures at the regenerator hot end during the intake and exhaust periods, respectively, and $\bar{T}_{\mathrm{Lc}}$ and $\bar{T}_{\mathrm{Le}}$ are the half-cycle mean temperatures at the regenerator cold end during the intake and exhaust periods, respectively.

If the thermal capacity flow of the regenerator matrix $C_{\mathrm{r}}$ is much larger than the thermal capacity flow of gas $C_{g}$, i.e. $C_{\mathrm{r}} / C_{\mathrm{g}}=\infty$, the effectiveness of a regenerator for oscillating flow is, according to Kays and London ${ }^{8}$

$\eta=\frac{N T U}{N T U+2}$

Combining Equation (3) with Equation (4), we obtain

$\frac{\bar{T}_{\mathrm{He}}-\bar{T}_{\mathrm{Le}}}{\bar{T}_{\mathrm{Hc}}-\bar{T}_{\mathrm{Le}}}=\frac{N T U}{N T U+2}$

where $N T U$ (number of transfer units) is defined as

$N T U=\frac{\bar{h} A_{\mathrm{T}}}{\overline{\bar{m}} C_{\mathrm{p}}}$

where: $\bar{h}$ is the mean heat convection coefficient in a half cycle; $A_{\mathrm{T}}$ is the surface area of the regenerator; $\overline{\dot{m}}$ is the half-cycle mean mass flowrate through the regenerator; and $C_{\mathrm{p}}$ is the heat capacity of the gas.

Equation (5) represents the half-cycle mean energy equation of the regenerator operated in oscillating flow. It is seen that the governing equation is greatly simplified. Solution of the non-linear time-variant differential equations for the regenerator can thus be avoided by using this halfcycle mean model.

For a regenerator made from a metal wire screen, $\bar{h}$ can be evaluated by the empirical correlation of Tanaka et al. . $\overline{N u}_{\mathrm{h}}=0.33 \overline{R e}_{\mathrm{h}}{ }^{0.67}$. Therefore

$\bar{h}=0.33\left(\frac{k_{\mathrm{g}}}{d_{\mathrm{h}}}\right)\left(\frac{\overline{\dot{m}} d_{\mathrm{h}}}{\mu_{\mathrm{g}} A_{r}}\right)^{0.67}$

where: $A_{\mathrm{T}}=\left(V_{\mathrm{r}} / \epsilon\right) 4(1-\epsilon) / d_{\mathrm{m}} ; d_{\mathrm{h}}$ is the hydraulic diameter of screen $=\epsilon d_{\mathrm{m}} /(1-\epsilon) ; d_{\mathrm{m}}$ is the screen wire diameter; and $\epsilon$ is the regenerator porosity. The thermal conductivity $k_{\mathrm{g}}$ and the viscosity $\mu_{\mathrm{g}}$ of helium gas are corrected according to the operating temperature ${ }^{10}$.

Instantaneous governing equations of GiffordMcMahon cooler. Three control volumes (Figure 4), namely the expansion space (CV1), whole cylinder (CV2) and compression space (CV3), are used in the derivation of the instantaneous governing equations. For low frequency operation of the GM cooler, the quasi-steady assumption

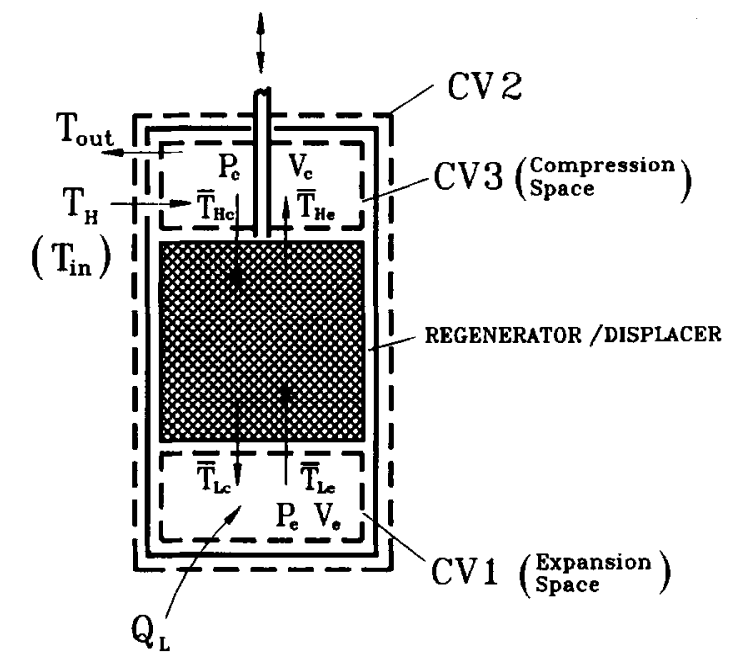

Figure 4 Control volume definition in the system analysis

can hold for the relation between the mass flowrate and the pressure drop across the valve and the regenerator ${ }^{6}$.

In the intake period, the momentum equation for the flow through the control valve is

$p_{\mathrm{H}}-p_{\mathrm{c}}(t)=K_{\mathrm{v} 1} \dot{\mathrm{m}}_{\mathrm{v}}(t)+K_{\mathrm{v} 2} \dot{m}_{\mathrm{v}}{ }^{2}(t)$

The momentum equation for the regenerator at quasi-steady state is basically Darcy's law

$p_{\mathrm{c}}(t)-p_{\mathrm{e}}(t)=\alpha \dot{m}_{\mathrm{r}}(t)+\beta \dot{m}_{\mathrm{r}}^{2}(t)$

Taking the mass balance of the compression and expansion spaces into account leads to the following equations

$\frac{1}{R \bar{T}_{\mathrm{c}}} \frac{\mathrm{d}}{\mathrm{d} t}\left(p_{\mathrm{c}} V_{\mathrm{c}}\right)+\dot{m}_{\mathrm{r}}-\dot{m}_{\mathrm{v}}=0$

$\frac{1}{R \bar{T}_{\mathrm{c}}} \frac{\mathrm{d}}{\mathrm{d} t}\left(p_{\mathrm{e}} V_{\mathrm{e}}\right)-\dot{m}_{\mathrm{r}}=0$

Similarly, the mass and momentum equations for the exhaust period are

$p_{\mathrm{c}}(t)-p_{\mathrm{L}}=K_{\mathrm{v} 1} \dot{m}_{\mathrm{v}}(t)+K_{\mathrm{v} 2} \dot{m}_{\mathrm{v}}{ }^{2}(t)$

$p_{\mathrm{e}}(t)-p_{\mathrm{c}}(t)=\alpha \dot{m}_{\mathrm{r}}(t)+\beta \dot{m}_{\mathrm{r}}^{2}(t)$

$\frac{1}{R \bar{T}_{\mathrm{c}}} \frac{\mathrm{d}}{\mathrm{d} t}\left(p_{\mathrm{c}} V_{\mathrm{c}}\right)+\dot{m}_{\mathrm{v}}-\dot{m}_{\mathrm{r}}=0$

$\frac{1}{R \bar{T}_{\mathrm{e}}} \frac{\mathrm{d}}{\mathrm{d} t}\left(p_{\mathrm{e}} V_{\mathrm{e}}\right)+\dot{m}_{\mathrm{r}}=0$

The volumes of the compression and expansion spaces, $V_{\mathrm{c}}(t)$ and $V_{\mathrm{e}}(t)$, for a mechanically-driven displacer can be expressed as

$V_{\mathrm{c}}(t)=V_{\mathrm{cD}}+e A_{\mathrm{d}}[1+\cos (2 \pi f t)]$

$V_{\mathrm{e}}(t)=V_{\mathrm{eD}}+e A_{\mathrm{d}}[1-\cos (2 \pi f t)]$ 
where $e$ is the eccentric length of the cam drive and $A_{\mathrm{d}}$ is the cross-sectional area of the displacer. The half-cycle mean energy equation of the regenerator is represented by Equation (5).

Equations (7)-(16) are the governing equations of the GM cooler at transient states.

\section{System performance analysis}

\section{Net cooling capacity}

Applying the laws of energy balance to the expansion space (CV1), we obtain the maximum available cooling capacity $Q_{\max }$

$Q_{\text {mlax }}=f \oint p_{\mathrm{e}}\left(\frac{\mathrm{d} V_{\mathrm{e}}}{\mathrm{d} t}\right) \mathrm{d} t-\overline{\dot{m}}_{\mathrm{r}} C_{\mathrm{p}}\left(\bar{T}_{\mathrm{Le}}-\bar{T}_{\mathrm{Le}}\right)$

Combining the energy equations of the cylinder (CV2) and compression space (CV3), we obtain

$Q_{\max }+\overline{\dot{m}}_{\mathrm{r}} C_{\mathrm{p}}\left(\bar{T}_{\mathrm{Hc}}-\bar{T}_{\mathrm{He}}\right)+f \oint p_{\mathrm{c}}\left(\frac{\mathrm{d} V_{\mathrm{c}}}{\mathrm{d} t}\right) \mathrm{d} t=0$

Thirumaleshwar and Subramanyam ${ }^{10}$ found experimentally that the major heat loss in a GM cooler is the motional heat loss or shuttle loss of the displacer $Q_{\mathrm{M}}$, which can be evaluated by the empirical relation ${ }^{3,10}$

$Q_{\mathrm{M}}=k_{\mathrm{g}} \pi D S^{2} C_{\mathrm{T}} \frac{T_{\mathrm{H}}-T_{\mathrm{L}}}{2 L c}$

where: $D$ is the displacer outside diameter; $S$ is the displacer stroke; $C_{\mathrm{T}}$ is the time fraction of heat transfer between the displacer and cylinder (for a displacer with harmonic motion $C_{\mathbf{T}}=0.2$ ); $L$ is the displacer length; and $c$ is the clearance between the displacer and the cylinder.

The net cooling capacity of a GM cooler is

$Q_{\mathrm{L}}=Q_{\max }-Q_{\mathrm{M}}$

\section{Performance index of GM cooler}

Coefficient of performance ( $C O P$ ) is used in the performance evaluation of a GM cooler; it is defined as

$C O P=\frac{Q_{\mathrm{L}}}{W_{c}}$

where $W_{c}$ is the input power which is taken as the adiabatic compression work, i.e.

$W_{\mathrm{c}}=\overline{\dot{m}}_{\mathrm{v}} C_{\mathrm{p}} T_{\mathrm{H}}\left[\left(\frac{p_{\mathrm{H}}}{p_{\mathrm{L}}}\right)^{(\gamma-1) / \gamma}-1\right]$

Another performance index for a GM cooler is the Carnot efficiency (\% Carnot), which is defined as

$\%$ Carnot $=100 \times \frac{\text { actual } C O P}{\text { Carnot } C O P}$ where Carnot $C O P$ is the $C O P$ of the ideal Carnot refrigerator defined as

Carnot $C O P=\frac{T_{\mathrm{I}}}{T_{\mathrm{H}}-T_{\mathrm{L}}}$

\% Carnot is used to judge how close the cooler performance is to that of an ideal Carnot cooler.

It should be noted that $T_{\mathrm{H}}$ in Equation (24) is taken as the compressed gas temperature at the inlet of the cylinder, i.e. $T_{\mathrm{H}}=T_{\mathrm{in}}$. COP thus does not include the efficiency of the gas compressor.

\section{System analysis procedure}

To simplify the system analysis, the following assumptions are made:

1 The heat loss in the connecting pipe between the compressor aftercooler and the cylinder is negligible. Therefore, the half-cycle mean temperature at the regenerator hot end in the intake period $\bar{T}_{\mathrm{Hc}}$ approximates $T_{\mathrm{H}}$, i.e.

$$
\bar{T}_{\mathrm{Hc}} \approx T_{\mathrm{H}}
$$

2 In the intake period, the half-cycle mean gas temperature at the regenerator cold end $\bar{T}_{\mathrm{Lc}}$ approximates the cold head temperature $T_{\mathrm{L}}$, i.e.

$$
\bar{T}_{\mathrm{Lc}} \approx T_{\mathrm{L}}
$$

The system inputs in the analysis of a GM cooler include the operating conditions $p_{\mathrm{H}}, p_{\mathrm{L}}, T_{\mathrm{H}}, T_{\mathrm{L}}$ and the geometric design specifications. For a given geometric design, a system performance simulation can be carried out. The analytical procedure is shown in Figure 5. The governing equa-

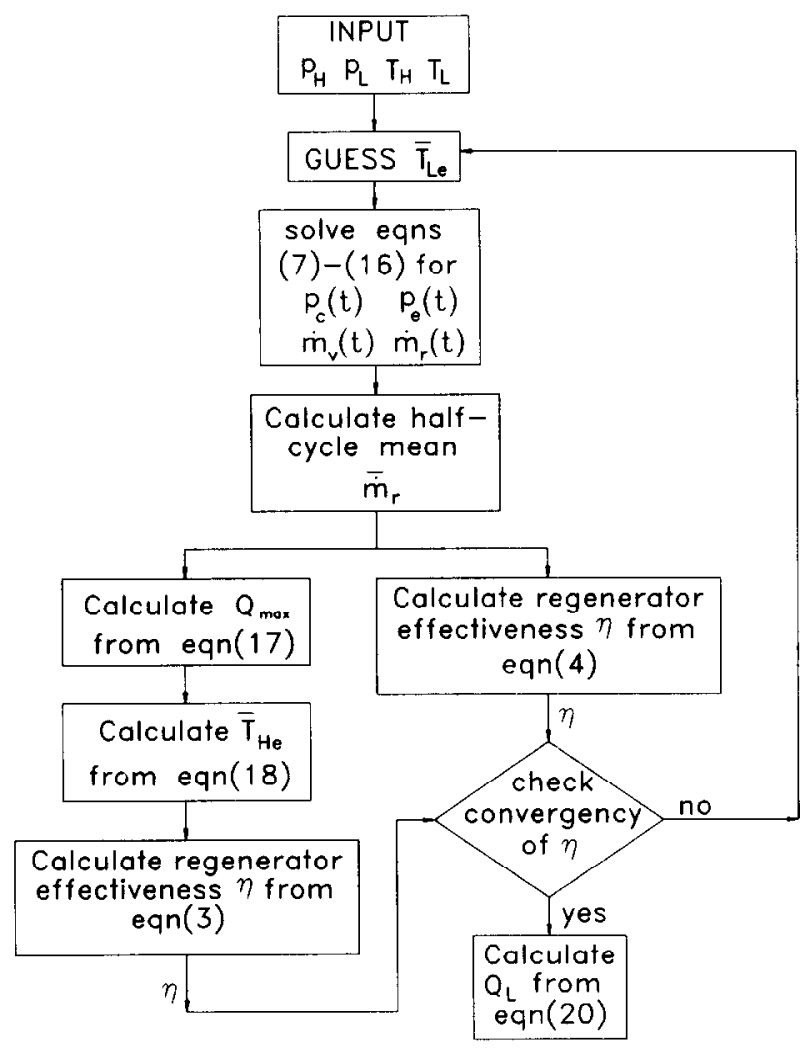

Figure 5 Simulation flow chart 
tions, Equations (6)-(17), for the instantaneous pressure and mass flowrate in the compression and expansion spaces are first solved numerically for a guessed $\bar{T}_{\mathrm{Le}}$. The halfcycle mean mass flow rate in the regenerator $\overline{\dot{m}}_{\mathrm{r}}$ is then evaluated. The calculated regenerator effectiveness $\eta$, determined using Equation (3) in conjunction with Equations (17) and (18), is compared with that calculated from Equation (4). An iteration process is then followed until convergence of $\eta$. Physical properties such as density, viscosity and thermal conductivity of the gas are also corrected iteratively according to the half-cycle mean temperature and pressure and the ideal gas law.

It is noted that the performance analysis can be divided into two parts. The first part includes the solution of transient Equations (6)-(17); the second part includes an algebraic calculation using the regenerator half-cycle mean energy equations, Equations (3) and (4). Since the transient equations (7)-(16) are solved numerically using the IMSL DGEAR subroutine and numerical solution of the regenerator transient equations is avoided, the performance analysis is simplified a great deal. A PC-based package GMSYS is developed in the present study and the entire computation for an analysis takes a few minutes with a PC 486.

\section{Experimental verification}

\section{Experimental set-up}

A single-stage GM cooler is designed and tested to verify the system performance analysis. The regenerator design is integrated with the displacer to form a displacer/regenerator component. The regenerator is $34.4 \mathrm{~mm}$ in diameter, $70 \mathrm{~mm}$ in length and $176 \mathrm{~g}$ in weight. The regenerator is made from 652 200-mesh phosphor bronze wire screen discs with a wire diameter of $0.042 \mathrm{~mm}$. The regenerator case is made from a phenolic fibre material with an outside diameter of $51.6 \mathrm{~mm}$, an inside diameter of $34.4 \mathrm{~mm}$ and weight of $197 \mathrm{~g}$.

The cold head (cylinder) is $\mathbf{1} 35.6 \mathrm{~mm}$ in length, $52.5 \mathrm{~mm}$ in inside diameter and $0.35 \mathrm{~mm}$ in wall thickness. The stroke of the displacer/regenerator is $25.4 \mathrm{~mm}$. The dead volumes of the compression and the expansion spaces are 3.46 and $5.09 \mathrm{~cm}^{3}$, respectively. The clearance between the displacer and the cylinder is $0.2 \mathrm{~mm}$ and the swept volume of the displacer is $55 \mathrm{~cm}^{3}$.

Helium gas of $99.999 \%$ purity is used as the working fluid. A CTI Model SC helium compressor is used in the present experiment. The charged pressure is $250 \mathrm{psig}$. During normal operation, the supplied pressure $p_{\mathrm{H}}=275 \mathrm{psig}$ and the return pressure $p_{\mathrm{L}}=110 \mathrm{psig} *$. The vacuum chamber is evacuated to below $10^{-6}$ torr $\dagger$ by an Osaka OVTH162 turbopump. A thermocouple made from KPvsAu7Fe material and a YEW7563 digital thermometer are used to measure the cold end temperature.

\section{Determination of valve constants}

Darcy's law used to describe the pressure drop across the valve [Equations (7) and (11)] has two empirical constants, $K_{\mathrm{v} 1}$ and $K_{\mathrm{v} 2}$, which have to be determined experimentally. Since the valve is simply a small hole, we measure the

\footnotetext{
* 1 psi $=6894.76 \mathrm{~N} \mathrm{~m}^{-2}$

1 torr $=133.322 \mathrm{~N} \mathrm{~m}^{-2}$
}

pressure drop at various mass flowrates and obtain the following correlation for the frictional coefficient

$f=\frac{95398}{R e}+0.329$

where $R e$ is the Reynolds number defined with respect to the hole diameter $D$ of the valve, which is $5 \mathrm{~mm}$. That is, $R e=\rho u_{v} D / \mu=\dot{m}_{\mathrm{v}} D /\left(\frac{1}{4} \pi D^{2} \mu\right)$.

Converting the above relation into the pressure drop of helium gas flow across the valve, we obtain

$$
\begin{aligned}
\Delta p= & -2.5378 \times 10^{9} \dot{m}_{\mathrm{v}}^{2}+1.1129 \times 10^{8} \dot{m}_{\mathrm{v}} \\
& -9.973 \times 10^{4} \mathrm{~Pa}
\end{aligned}
$$

Therefore, the valve constants $K_{\mathrm{v} 1}$ and $K_{\mathrm{v} 2}$ are determined as

$$
\begin{aligned}
& K_{\mathrm{v} 1}=1.1129 \times 10^{8} \mathrm{~Pa} \mathrm{~kg}^{-1} \mathrm{~s}^{-1} \\
& K_{\mathrm{v} 2}=-2.5378 \times 10^{9} \mathrm{~Pa} \mathrm{~kg}^{-2} \mathrm{~s}^{-2}
\end{aligned}
$$

\section{Experimental results}

It can be seen from Figure 6 that the predicted $Q_{\mathrm{L}}$ agrees with the simulation results to within $\pm 15 \%$ for the cold head temperature $T_{\mathrm{L}}<120 \mathrm{~K}$ (or $Q_{\mathrm{L}}<50 \mathrm{~W}$ ). It is also shown that for $T_{\mathrm{L}}>120 \mathrm{~K}$ (or $Q_{\mathrm{L}}>50 \mathrm{~W}$ ), the predicted $Q_{\mathrm{L}}$ is smaller than the test results and the deviation increases with increasing $T_{\mathrm{L}}$. This is due to the approximation $\bar{T}_{\mathrm{Lc}} \approx T_{\mathrm{L}}$ [Equation (26)] used in the simulation for all cases. Equation (26) implies that the convective heat transfer between the gas in the expansion space and the cold head wall is assumed to be very large. This may be true only for cases of low $Q_{\mathrm{L}}$ or $T_{\mathrm{L}}$.

The half-cycle mean temperature at the regenerator cold end in the intake period $\bar{T}_{\mathrm{Le}}$ is expected to be equal to the cold head temperature $T_{\mathrm{L}}$ only for low $T_{\mathrm{L}}(<120 \mathrm{~K})$ with lower cooling capacity $\left(Q_{\mathrm{L}}<50 \mathrm{~W}\right)$. The deviation between $\bar{T}_{\mathrm{Lc}}$ and $T_{\mathrm{L}}$ thus increases and causes a larger error in $Q_{\mathrm{L}}$ when $T_{\mathrm{L}}$ is high.

To verify this, a thermocouple with $0.075 \mathrm{~mm}$ diameter wire was installed inside the expansion space to measure the instantaneous gas temperature using a fast digital recorder YEW 3655E. The test results show that $T_{\mathrm{L}}-\bar{T}_{\mathrm{Lc}}$ $=10 \mathrm{~K}$ at $T_{\mathrm{L}}=80 \mathrm{~K}$ and $Q_{\mathrm{L}}=35 \mathrm{~W} ; T_{\mathrm{L}}-\bar{T}_{\mathrm{Lc}}=20 \mathrm{~K}$ at $T_{\mathrm{L}}=100 \mathrm{~K}$ and $Q_{\mathrm{L}}=47 \mathrm{~W}$; and $T_{\mathrm{L}}-\bar{T}_{\mathrm{Lc}}=75 \mathrm{~K}$ at $T_{\mathrm{L}}=$ $200 \mathrm{~K}$ and $Q_{\mathrm{L}}=82 \mathrm{~W}$, as shown in Figure $7 a$. The convective heat transfer coefficient of the helium gas in the expansion space evaluated from the test data is also seen to be very high at low $T_{\mathrm{L}}$ as shown in Figure $7 b$.

The discrepancy between the predicted $Q_{\mathrm{L}}$ and the test results may also be caused by the following factors:

1 The half-cycle mean energy equation of the regenerator [Equation (4)] is accurate if $C_{\mathrm{r}} / C_{\mathrm{g}} \rightarrow \infty$. However, the thermal capacity flow of the regenerator matrix $C_{\mathrm{r}}$ may decrease dramatically at an operating temperature $<80 \mathrm{~K}$ such that the assumption of $C_{\mathrm{r}} / C_{\mathrm{g}}=\infty$ becomes invalid.

2 The displacer shuttle loss $Q_{\mathrm{M}}$ is probably underestimated, since the clearance $c$ between the cylinder and the displacer may be smaller at higher temperature due to differential shrinkage of the cylinder and the displacer. 
GM Cooler S2

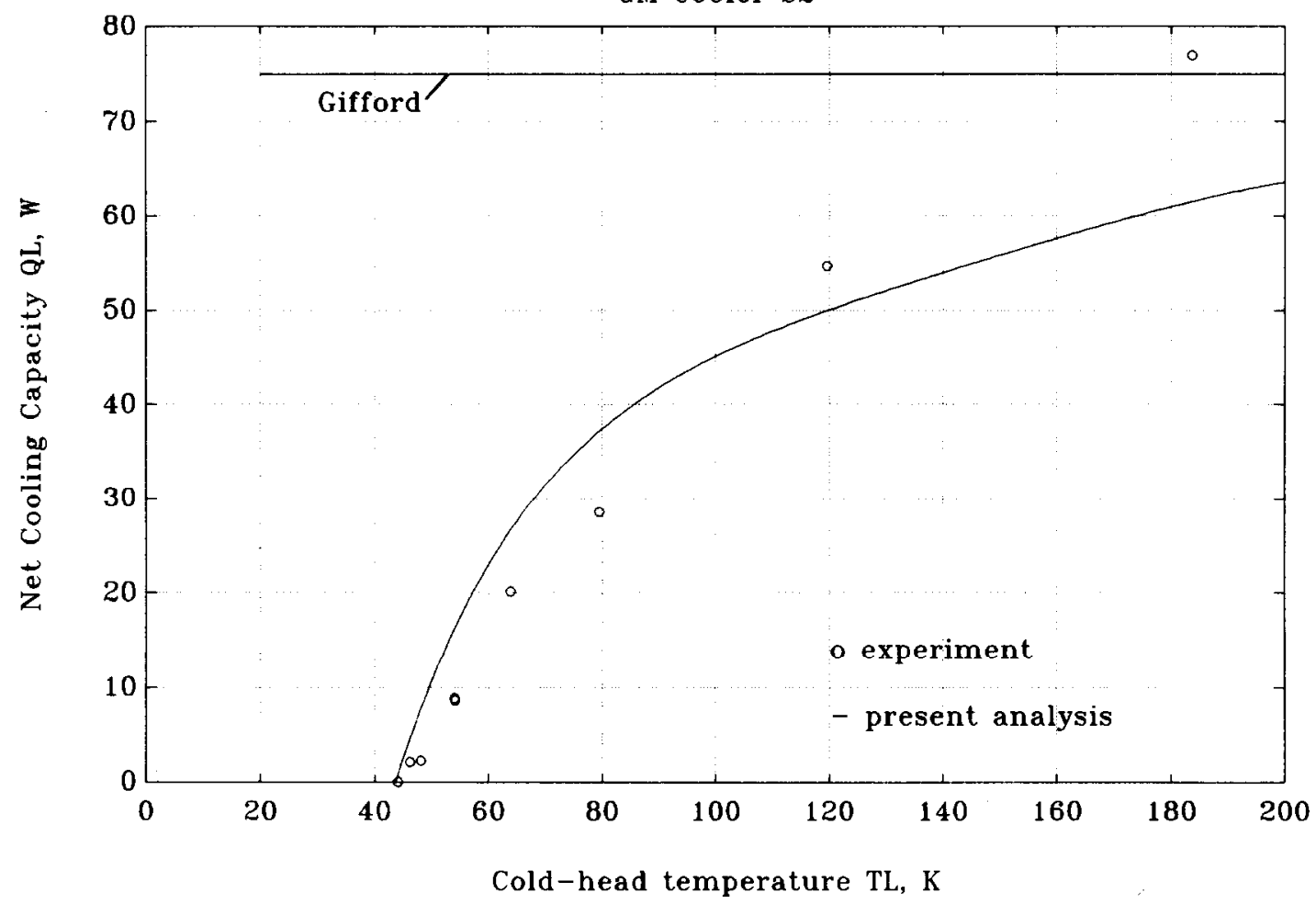

Figure 6 Comparison of test results with simulation
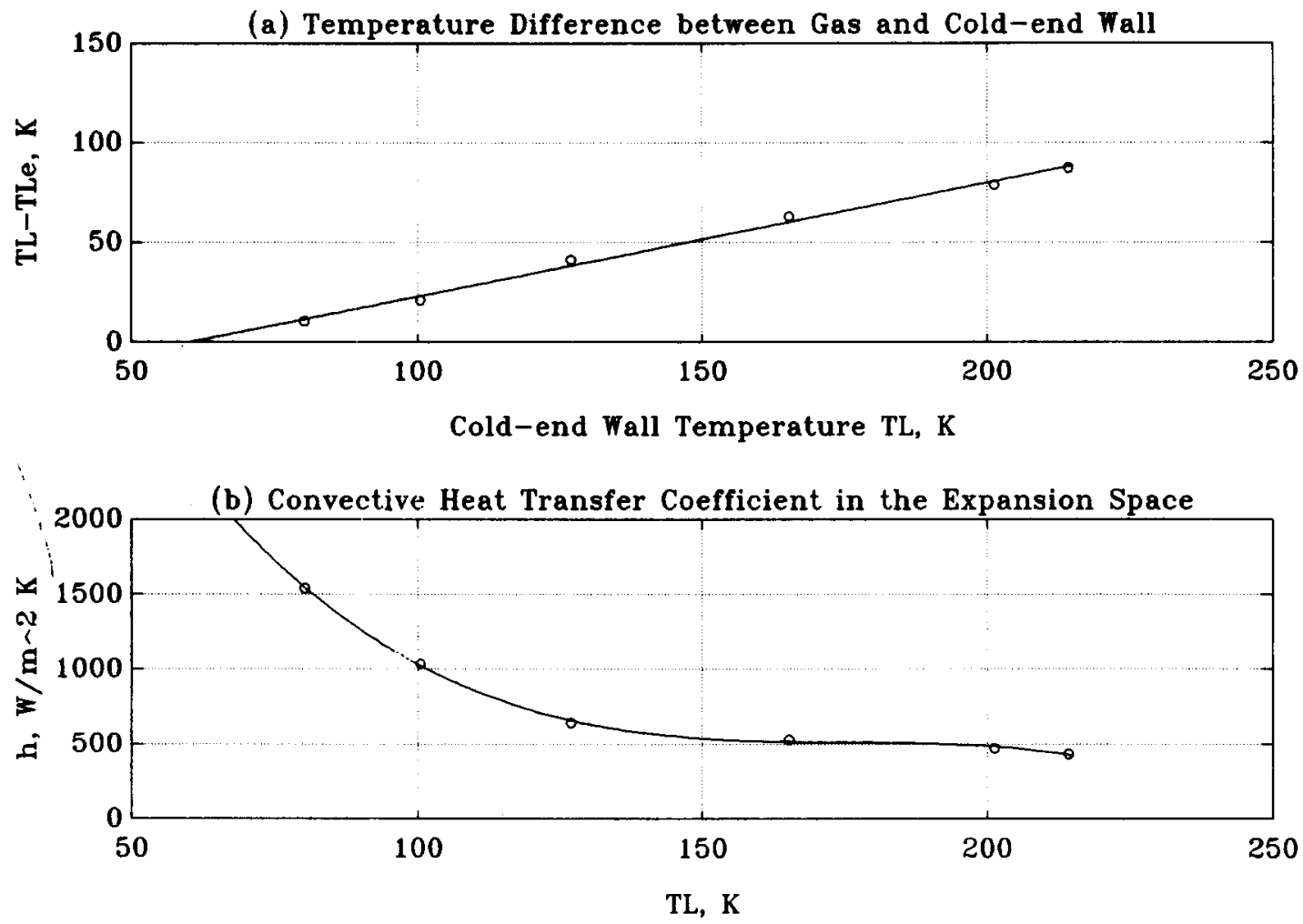

Figure 7 (a) Deviation of cold end temperature; (b) convective heat transfer coefficient in the expansion space

3 The conduction loss of the regenerator and the gas leakage loss through the displacer clearance are not taken into account.

To assess the energy efficiency of the GM cooler, the energy efficiency ratio $(E E R)$ can be defined as the ratio of the cooling capacity to the total power input, including power consumed by the compressor, fans, motor, etc.
$E E R=\frac{Q_{\mathrm{L}}}{W_{\text {total }}}$

The overall Carnot efficiency $\%$ Carnoto can also be defined as the ratio of EER to Carnot COP defined in Equation (23), i.e.

$\%$ Carnot $0=\frac{E E R}{\text { Carnot } C O P}$ 
Performance analysis of GM cooler: B.J. Huang and S.C. Chang
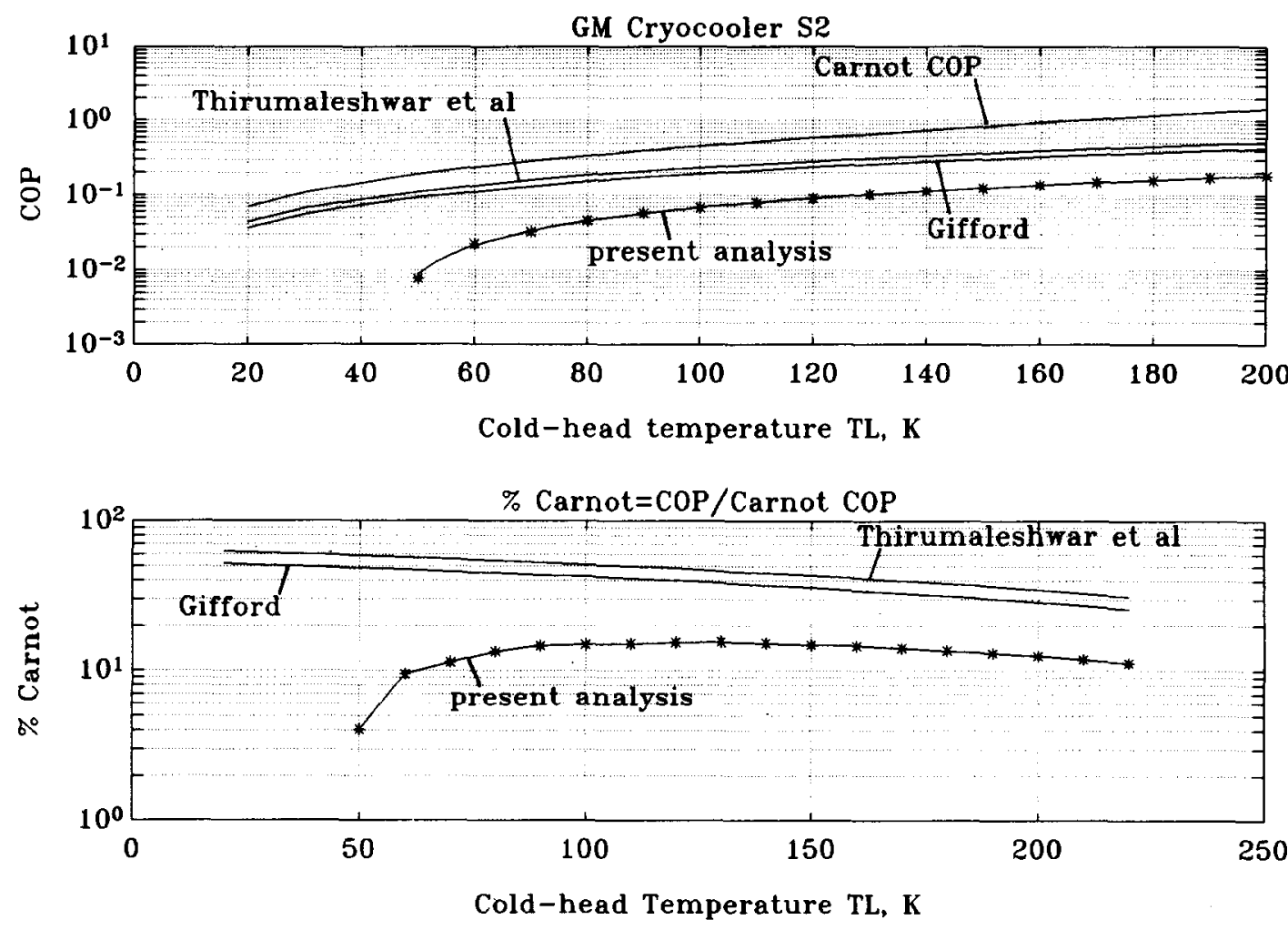

Figure 8 Comparison of analytical results using different models
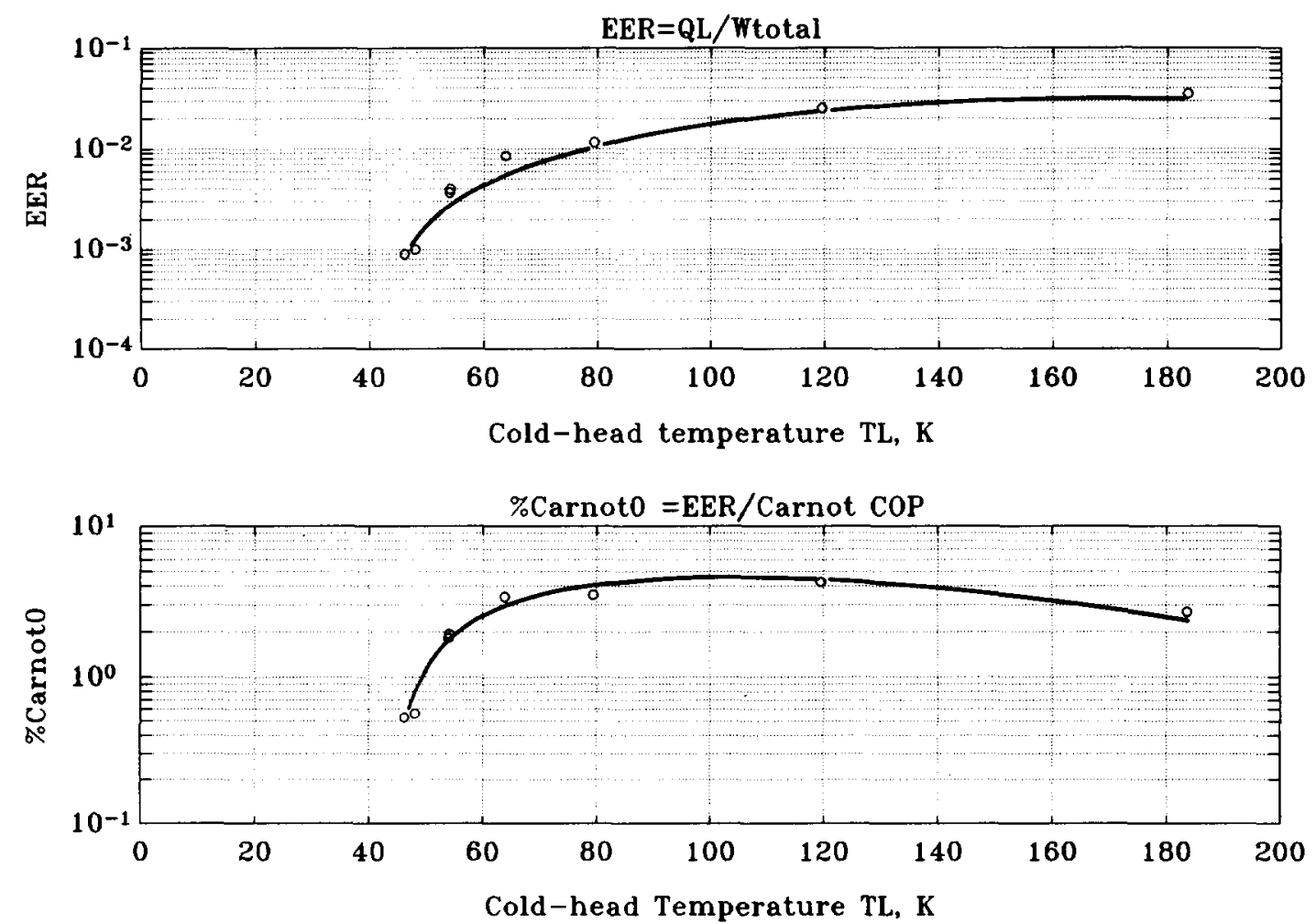

Figure 9 Test results for EER and \% Carnot 0 
The test results in Figure 9 show that the measured EER increases with $T_{\mathrm{L}}$ and the optimum \% Carnot 0 is found around $T_{\mathrm{L}}=100 \mathrm{~K}$.

The cold head temperature $T_{\mathrm{L}}$ of the single-stage GM cooler designed in the laboratory can reach a lowest temperature of $39 \mathrm{~K}$ at zero cooling capacity. A cooling capacity of $29 \mathrm{~W}$ is obtained at $T_{\mathrm{L}}=80 \mathrm{~K}$ with $E E R=$ 0.0116 . It was also found that the test results of $E E R$ versus $T_{\mathrm{L}}$ do not alter even if a different displacer/regenerator is used during the tests. This is caused by the fact that most of the total power input of the GM couler is consumed by the helium compressor which is designed with a special gas purification and oil separation device.

The $C O P$ and \% Carnot of the GM cooler can be evaluated from Equations (20)-(24). Gifford ${ }^{11}$ assumed that the compressor undergoes an adiabatic process and derived equations for $Q_{\mathrm{L}}, C O P$ and $\%$ Carnot

$$
\begin{gathered}
Q_{\mathrm{L}}=f V_{\text {swept }}\left(p_{\mathrm{H}}-p_{\mathrm{L}}\right) \\
C O P=\frac{R\left(r_{\mathrm{p}}-1\right)}{C_{\mathrm{p}}\left(r_{\mathrm{p}} r_{\mathrm{T}}-1\right)\left[r_{\mathrm{p}}^{(\gamma-1) / \gamma}-1\right]} \\
\% \text { Carnot }=100 \times \frac{\left(T_{\mathrm{H}}-T_{\mathrm{L}}\right) / T_{\mathrm{L}}}{C_{\mathrm{p}}\left(r_{\mathrm{p}} r_{\mathrm{T}}-1\right)\left[r_{\mathrm{p}}^{(\gamma-1) / \gamma}-1\right] / R\left(r_{\mathrm{p}}-1\right)}
\end{gathered}
$$

where $r_{\mathrm{p}}=p_{\mathrm{H}} / p_{\mathrm{L}} ; r_{\mathrm{T}}=T_{\mathrm{H}} / T_{\mathrm{L}}$.

Thirumaleshwar et al. $^{2}$ assumed that the compressor undergoes an isothermal compression process and derived the following results

$$
\begin{gathered}
C O P=\frac{r_{\mathrm{p}}-1}{\left(r_{\mathrm{p}} r_{\mathrm{T}}-1\right) \ln r_{\mathrm{p}}} \\
\% \text { Carnot }=100 \times \frac{\left(T_{\mathrm{H}}-T_{\mathrm{L}}\right) / T_{\mathrm{L}}}{\left[\left(r_{\mathrm{p}} r_{\mathrm{T}}-1\right) \ln r_{\mathrm{p}}\right] /\left(r_{\mathrm{p}}-1\right)}
\end{gathered}
$$

The analytical results using the above models are also shown in Figure 8. It is seen that $C O P$ values determined from the thermodynamic analysis of Gifford ${ }^{11}$ and Thirumaleshwar $e t a l^{2}$ are much higher than those from the present analysis. \% Carnot is shown to decrease monotonically with increasing $T_{\mathrm{L}}$ without an optimum value for the thermodynamic analysis ${ }^{2,11}$. However, \% Carnot is shown first to increase with increasing $T_{\mathrm{L}}$, reach a maximum value and then decrease in the present analysis. An optimum \% Carnot around $100 \mathrm{~K}$ exists. This can also be verified exper- imentally by the measured EER as shown in Figure 9, since $E E R$ is approximately proportional to \% Carnot.

\section{Conclusions}

A regenerator half-cycle mean energy model is derived in the present study to avoid transient heat transfer analysis of the regenerator. The dynamic equations of the mass and momentum balances of a GM cooler are first derived and solved numerically for the time variables $p_{\mathrm{e}}(t), p_{\mathrm{c}}(t), \dot{m}_{\mathrm{v}}(t)$, $\dot{m}_{\mathrm{r}}(t)$. The half-cycle mean variables are then calculated and used to compute the regenerator effectiveness using the regenerator half-cycle mean energy equation. Using an iteration scheme, the final solutions can be obtained, from which the system performance of the GM cooler can be evaluated. A PC-based simulation package GMSYS was also developed to carry out system analysis of a singlestage GM cryocooler. Finally it was shown experimentally that the performance prediction agrees with the test results very well.

\section{Acknowledgement}

The present study was supported by The Energy Commission, Ministry of Economic Affairs, Taiwan.

\section{References}

1 Gifford, W.E. The Gifford-McMahon cycle Adv Cryog Eng (1966) 11 152-159

2 Thirumaleshwar, M. and Subramanyam, S.V. Gifford-McMahon cycle - a theoretical analysis Cryogenics (1986) 26 177-188

3 Thirumaleshwar, M. and Subramanyam, S.V. Heat balance analysis of single stage Gifford-McMahon cycle cryocooler Cryogenics (1986) 26 189-195

4 Ackermann, R.A. and Gifford, W.E. Small cryogenic regenerator performance ASME J: Eng for Industry (Feb 1969) 273-281

5 Minas, C. and Hualde, P.M. Dynamic modelling of a GiffordMcMahon cryorefrigerator Cryogenics (1992) 32 634-639

6 Huang, B.J. and Lu, C.W. Dynamic response of regenerator in cyclic flow system Cryogenics (1993) 33 1046-1052

7 Qvale, E.B. and Smith, J.L. Jr An approximate solution for the thermal performance of a Stirling-engine regenerator Trans ASME J: Eng. for Power (April 1969) 109-112

8 Kays, W.M. and London, A.L. Compact Heat Exchangers 2nd Edn, McGraw-Hill, New York, USA (1984)

9 Makoto, T., Iwao, Y. and Fumitake, C. Flow and heat transfer characteristics of the Stirling engine regenerator in an oscillating flow JSME Int J: Series II (1990) 33(2) 283-289

10 Thirumaleshwar, M. and Subramanyam, S.V. Energy analysis of a Gifford-McMahon cycle cryorefrigerator Cryogenics (1986) 26 248-251

11 Gifford, W.E. The Gifford-McMahon cycle Adv Cryog Eng (1965) 11 152-159 